\title{
Parques patrimoniais (agrários, fluviais, geoparques): 0 território das águas
}

\author{
HeRItAGe PARKS (AGRARIAN, RIVERPARKS, GEOPARKS): the WATER terRITORY
}

André Munhoz de Argollo Ferrão ${ }^{1}$

1-Professor livre Docente do Departamento de Recursos Hídricos da Faculdade de Engenharia Civil, Arquitetura e Urbanismo da Unicamp. Professor do PEHCT/IG-UNICAMP. CampINAs [SP] Brasil. ARGOLLo@fec.unICAMP.BR

Abstract: Regional development projects in the twentieth century mainly favored efficiency and technical rationality, but did not consider local realities and the real needs of the communities involved. It is essential to know and respect the cultural aspects related to the use and management of water in every region and in every society, because the key issue of water resources management processes is not purely technical, but stems from ignorance of the socio-cultural dimension before, during and after the implementation of these projects and policies. This article seeks to associate the idea of heritage parks (agrarian, riverparks, geoparks), water and land systems, and culture as territorial planning instruments, under integrated watershed management programs.

\section{Manuscrito:}

Recebido: 12/out/16

Corrigido: $27 /$ nov/17

Aceito: $14 / \mathrm{fev} / 18$

Citation: Argollo Ferrao A.M.de. 2018. Parques patrimoniais (agrários, fluviais, geoparques): 0 território das águas. Terræ Didatica, 14(1):39-48. URL: http://www.ige.unicamp.br/terraedidatica/.

Keywords: Cultural landscape, water resources, watershed management, agrarian parks, riverparks, geoparks.

\section{Introdução}

A noção que normalmente se concebe sobre um determinado território pode revelar limitações importantes, pois os ecossistemas e os corpos hídricos nem sempre se ajustam aos limites administrativos artificialmente definidos pelo homem. Os territórios sofrem transformações contínuas que acarretam outras transformações em diferentes escalas no meio rural, no meio urbano e nas áreas ambientalmente protegidas resultando em novos territórios adaptados, sobrepostos e interligados, num processo de sucessivas transformações.

A simples definição de um limite espacial concreto não implica necessariamente a conformação de um território, pois que este se define pelas relações sociais a partir do seu uso e também pelas relações de poder que nele (por ele ou sobre ele) se estabelecem. Tais relações são chamadas de territorialidades e são compreendidas por intermédio dos processos sociais e culturais que um determinado grupo mantém com a rede de lugares e itinerários que constitui o seu território, em diferentes escalas: bairro, cidade, campo, região, país etc.

As relações de poder se materializam no território por intermédio de políticas envolvendo a sociedade e o espaço que ela utiliza. O processo de gestão pública é conduzido por instâncias de governo e por instituições formadas a partir das representações dos interessados no objeto da gestão, nos seus procedimentos, instrumentos e recursos. Compreender as territorialidades é essencial para o bom planejamento e a concepção de projetos sustentáveis de gestão territorial, capazes de equilibrar as relações territorializadas de poder e gerenciar os conflitos de interesse que se manifestam na apropriação e definição do espaço, fortalecendo o Sistema Territorial local.

O termo "urbanismo", frequentemente utilizado no mesmo contexto do termo "planejamento urbano”, tem sua designação como ciência e arte de ordenação urbana atribuída ao arquiteto espanhol Ildefonso Cerdá, que o registrou pela primeira vez em 1867, na sua Teoria Geral da Urbanização (MonteMór 2006, p.62). A nova disciplina teria sido criada para a construção da cidade industrial. De fato, desde o fim do século XIX muitas transformações socioeconômicas e técnico-científicas alteraram a fisionomia das cidades; no entanto, o urbanismo deverá absorver no século XXI uma postura transdisciplinar frente à complexidade dos territórios cada vez mais urbanizados, associando-se às geociências, à engenharia, à economia, sociologia e demais disciplinas do território, focando, certamente, 
a gestão integrada dos recursos hídricos e demais recursos naturais.

A bacia hidrográfica é a unidade territorial para implementação da Política Nacional de Recursos Hídricos e atuação do Sistema Nacional de Gerenciamento de Recursos Hídricos (Brasil 1997), de acordo com a Lei 9.433/97, a chamada Lei das Águas que, além de direcionar a gestão desse precioso bem - patrimônio da humanidade -, influencia também a gestão urbana e regional, já que as bacias abrangem os territórios municipais assim como as regiões administrativas.

Chega-se ao desenvolvimento sustentável com as geociências, a engenharia e o urbanismo promovendo uma perfeita articulação da gestão dos recursos hídricos com a gestão do patrimônio (ambiental e cultural) no âmbito de um determinado território. Um instrumento capaz de atender tais pretensões são os "Parques Patrimoniais" que, por intermédio de estratégias competentes para a gestão do uso da terra e das águas, garantindo a proteção das margens dos cursos d'água, podem representar um novo modelo de desenvolvimento territorial - a favor da sustentabilidade e do respeito pelas identidades locais. Constituem diferentes tipos de parques patrimoniais os "Parques Agrários", os "Parques Fluviais" e os "Geoparques", dentre outros.

A Constituição Federal de 1988 possibilitou novas formas de participação da sociedade civil no envolvimento com as políticas públicas. Os dispositivos constitucionais criados fortaleceram a dinâmica de descentralização da ação pública e estabeleceram formas diferentes de compartilhar responsabilidades entre os governos federal, estaduais e municipais, exigindo maior conhecimento e respeito para com a identidade dos diferentes sistemas e subsistemas hídrico-territoriais que compõem o Território Nacional.

A identidade de um território se reconhece pelas marcas impregnadas por processos naturais e culturais que se desenrolam sobre ele ao longo do tempo. Natureza e Cultura compõem assim a identidade de um território. Pode-se dizer que o conjunto composto pelo patrimônio ambiental e pelo patrimônio cultural dispersos sobre um determinado território confere a ele a sua essência, ou a aura que o caracteriza.

As dinâmicas que se estabelecem entre Natureza e Cultura em macro escala, abrangendo mesmo regiões inteiras, exigem conhecimento técnico-científico específico e multidisciplinar, mas não prescindem do conhecimento transdisciplinar para se chegar ao reconhecimento e valorização da essência - ou identidade - do "lugar". Só se pode valorizar o que se conhece, todavia o valor que se imputa corresponde necessariamente à importância que se dá. Ou seja: não existe valorização sem contexto. Tudo que vale, vale para alguém, e a partir daí pode se tornar recurso. Todavia, a água presente em determinado território há de ser reconhecida como elemento essencial da paisagem correspondente - esta, entendida como a resultante das inter-relações entre o homem e seu meio ambiente. A água deve ser seriamente considerada nas decisões politicas, econômicas e científicas para a preservação e/ou resolução dos problemas relacionados ao [seu] uso e gestão (Franca 2009), o que requer um exame profundo para o planejamento dos recursos hídricos. Há de se conferir a mesma importância à dimensão cultural da água.

\section{As dimensões econômica e cultural da água}

A água é imprescindível, essencial e insubstituível. Reconhecida pela Lei Federal no 9.433/97, em seu Artigo $1^{\circ}$, como um recurso natural limitado, dotado de valor econômico (BRASIL 1997), a água é um recurso no sentido econômico do termo. Recursos econômicos são os meios materiais ou imateriais empregados na produção de bens e serviços para a satisfação das necessidades de uma sociedade, sendo responsáveis pelo desenvolvimento socioeconômico ou a falta dele. Os "recursos naturais" constituem uma categoria dos "recursos econômicos" ao se considerar a extração de bens da natureza para a sua transformação e utilização. Dentre os recursos naturais mais importantes do planeta estão a água e $\mathrm{o}$ ar. Os recursos não são: eles se tornam. Assim, a ideia da demanda seria fundamental para historicizar [ou contextualizar] a definição de recurso natural (Venturri 2006, p.11).

Todavia, assim como os recursos econômicos, o patrimônio também pode referir-se a várias categorias, dependo do contexto. Na Europa e nos Estados Unidos o patrimônio como recurso local ou, os recursos patrimoniais locais -, no âmbito das políticas públicas de desenvolvimento, é utilizado como instrumento de gestão territorial. A palavra patrimônio remete à ideia de herança ou espólio de uma geração passada às futuras, ou simplesmente como objeto de processos documentais. Patrimônio pode ter o sentido de estrutura (familiar, econômica ou jurídica), bem durável de valor cultural, histórico, territorial, hídrico, energético, ambiental. Patrimônio pode ser objeto de tombamento.

\begin{tabular}{c|c|c|c|c|c}
\hline (C) Terrae Didat. & Campinas, SP & v.14 & n.1 & p. 39-48 & jan./mar. 2018 \\
\hline \multicolumn{4}{|c|}{40}
\end{tabular}


O significado de patrimônio remete à ideia de um conjunto de elementos que possuem valor. Ora, se possuem valor, então alguém lhes dá o valor, ou seja, "possuem valor para alguém", seja um indivíduo, uma família, um grupo ou uma comunidade, toda a sociedade, a população de um município, estado ou país, ou mesmo toda a humanidade. Quando determinados elementos do conjunto patrimonial de uma certa categoria são "empregados na produção de bens e serviços para a satisfação das necessidades de uma sociedade", então este elemento se converte em recurso. Daí que para toda categoria patrimonial existe uma correspondente categoria de recursos.

Assim, os recursos naturais de um determinado território advêm do correspondente patrimônio natural desse mesmo território; os recursos hídricos advêm do correspondente patrimônio hídrico, e assim por diante. Por outro lado, o patrimônio cultural de uma comunidade pode disponibilizar os recursos culturais de que ela necessita para se desenvolver. Portanto, ao se considerar o patrimônio de uma sociedade, pode-se empregar os correspondentes recursos patrimoniais em processos e empreendimentos sustentáveis de tal modo que não se promova a dilapidação de toda a sua riqueza. O uso que se dá aos recursos patrimoniais de um território reflete o nível da gestão e o grau de conservação do patrimônio correspondente.

O conceito de patrimônio pode ser aplicado, portanto, no contexto da regulação do uso e ocupação do solo, como instrumento de planejamento visando o desenvolvimento territorial, em áreas de intervenção muito diversas, mas em geral vinculadas a processos de requalificação, revitalização e dinamização, como é o caso da maioria dos rios e corpos d'água.

A água é um elemento natural, mas quando se lhe atribui um valor econômico torna-se recurso - no caso, recurso hídrico. As políticas públicas de desenvolvimento deveriam associar o conceito de patrimônio hídrico ao de recurso hídrico e empregar instrumentos de preservação do patrimônio "água" no contexto dos planos diretores municipais e de bacias hidrográficas - que, integrados, poderiam regular o uso e ocupação do solo com maior eficiência e eficácia, principalmente nos processos de revitalização dos rios e cidades de uma mesma região.

A água é essencial para a saúde e a sustentabilidade das cidades. Também pode ser um vetor de transmissão de doenças, principalmente se os sistemas hídricos urbanos forem transformados em pontos de destinação de efluentes sem tratamento. O desenvolvimento econômico a partir de 1970 no Brasil acelerou o crescimento populacional e intensificou as atividades produtivas, incrementando consideravelmente os processos de urbanização nas regiões mais industrializadas do País, acarretando efeitos nocivos para a estrutura das cidades - que, sem planejamento, começaram a inchar desordenadamente em vez de crescer inteligentemente. Todo esse processo provocou o aumento da demanda por recursos hídricos, em alguns casos gerando conflito entre os usuários. Por outro lado, a degradação quantitativa e qualitativa do recurso despertou a consciência de muitos e o reconhecimento de que a água é um recurso natural - essencial, porém finito. A ação predatória motivada por interesses imediatistas nas cidades afeta a qualidade de vida e a paisagem urbana, degradando os sistemas territoriais locais.

\section{Planejamento da paisagem e do território}

A paisagem representa muito mais que a dimensão espacial e estética de um território, pois ela condiciona uma identidade - uma combinação única de fatores e processos ecológicos, culturais e socioeconômicos - bem como uma percepção emotiva por parte de quem a observa ou a vivencia. Ao território atribui-se o significado de área extensa com uma função específica. O ordenamento territorial envolve a associação de forma e função de elementos arquitetônicos e paisagísticos visando a organização de usos no espaço e no tempo, portanto constitui instrumento essencial para o desenvolvimento integrado e sustentável.

De acordo com Kevin Lynch (1960) há que se ressaltar a essência de cada lugar, pois a aura de uma cidade - ou bairros de uma cidade - compóe a imagem que se tem deles, com elementos muitas vezes imateriais. Portanto, a necessidade de [se] reconhecer e padronizar nosso ambiente é crucial e tem raízes tão profundamente arraigadas no passado, que essa imagem é de enorme importância prática e emocional para o indivíduo (Lynch 1960, p.04).

Um território não se restringe a uma simples combinação de espaços interdependentes - regiões, bairros, quarteirões, propriedades ou parcelas rurais, lotes, etc. - em que se poderia intervir a partir de análises superficiais normalmente apressadas, correspondendo a interesses escusos, particulares ou públicos, com objetivos setoriais e econômicos de curto prazo. Esse modo de 
agir sobre o território é incompatível com o conceito de ordenamento territorial. Por sua vez, a paisagem de uma determinada região não é apenas formada por volumes, mas também por cores, sons, movimentos, cheiros, a história do lugar, a organização desses lugares e tudo o que possa dar identidade àqueles que nele sintam-se bem; pois $a$ dimensão da paisagem é a dimensão da percep̧̧ão, o que chega aos sentidos (Santos 1988, p. 21).

O Brasil possui paisagens diversificadas e diferenciadas, marcadas por uma cultura muito rica e original. A proteção de tamanha riqueza deve ser garantida por lei, e a gestão competente desse imenso patrimônio nacional deve ser objeto de políticas públicas responsáveis e apropriadas ao contexto regional, em cada caso. A chancela da paisagem cultural é um instrumento criado para promover a preservação ampla e territorial de porções singulares do Brasil (IPHAN 2009, p.13).

Segundo Braga (2011), no século XXI as propostas mais interessantes para o planejamento urbano e regional - e também para os mais inovadores empreendimentos de engenharia - serão baseadas em um novo binômio que define a eficiência econômica e ecológica dos processos a elas intrínsecos: natureza e cultura. Os incentivos e os projetos de valorização territorial na Europa e nos Estados Unidos acontecem onde os territórios são marcados por atividades produtivas, como uma maneira de preservar as paisagens culturais em âmbito regional. Milton Santos salienta que:

(...) paisagem é um conjunto de formas que, num dado momento, exprime as heranças que representam as sucessivas relações localizadas entre homem e natureza. O espaço são as formas mais a vida que as anima (Santos 2006, p.103).

Atualmente a paisagem constitui tema de diferentes disciplinas acadêmicas e foco das múltiplas atividades humanas sobre o território - seja como resultante ou como fator preponderante - capaz de conformar a identidade de um lugar, a aura de uma região. O professor Carl Sauer, da Universidade de Berkeley, em seu livro A Morfologia da Paisagem (publicado em 1925), foi o primeiro acadêmico a conceituar determinadas paisagens como uma paisagem cultural - resultante das transformações da paisagem natural devidas à ação do ser humano, bem como das relações de mudança em seus hábitos e seu habitat. Assim explicava o autor: a cultura é o agente; o natural é o meio; e a paisagem cultural é o resultado (Sauer 1925).
No Brasil, a chancela da Paisagem Cultural Brasileira criada pelo IPHAN em 2009 constitui-se em importante instrumento de reconhecimento do valor patrimonial de determinados territórios e de suas paisagens correspondentes, conforme a Portaria n ${ }^{\circ}$ 127/2009 que estabelece: a Paisagem Cultural Brasileira é a porção peculiar do território nacional, representativa do processo de interação do homem com o meio natural, à qual a vida e a ciência humana imprimiram marcas ou atribuíram valores (IPHAN 2009, p.13). A chancela representa uma inovação para quem trabalha com o patrimônio. Mesmo não sendo o único órgão responsável pela preservação das paisagens brasileiras, a chancela do IPHAN tornou-se instrumento articulador de ações de valorização, planejamento e gestão do patrimônio "paisagem".

Segundo o Ministério do Meio Ambiente, o planejamento das cidades no Brasil é prerrogativa constitucional da gestão municipal que responde, até mesmo, pela delimitação oficial da zona urbana, rural e demais territórios para onde são direcionados os instrumentos de planejamento territorial. Os principais são o Zoneamento Ecológico-Econômico, o Plano Diretor Municipal, o Plano de Bacia Hidrográfica, o Plano Ambiental Municipal, a Agenda 21 Local, e o Plano de Gestão Integrada da Orla (para cidades praianas ou ribeirinhas). No entanto, todos os planos setoriais ligados à qualidade de vida no processo de urbanização, como saneamento básico, moradia, transporte e mobilidade, também constituem instrumentos de planejamento ambiental (Brasil 2014).

Determinadas porções do território cortadas por rios ou banhadas por corpos d'água podem receber a chancela de paisagem cultural por serem reconhecidas como um recurso patrimonial. Os planos de bacias hidrográficas integrados com os planos diretores municipais podem mapear e proteger com maior eficiência, além de promover a requalificação, revitalização ou dinamização dessas áreas. A chancela representa um pacto entre o poder público, a sociedade civil e a iniciativa privada, que promove a gestão compartilhada do território.

\section{Os parques patrimoniais como agentes de ordenamento territorial e indutores do desenvolvimento regional}

A ideia de parque está associada à natureza, à paisagem, ao urbano e ao não-urbano. Os parques estão em constante processo de redefinição, mas 
basicamente são áreas que contêm representações similares. Existem vários tipos de parque, dentre eles estão os parques: urbano, natural, nacional, estadual e municipal.

- Parque urbano corresponde a um espaço livre normalmente caracterizado como espaço público. Surge da necessidade de áreas verdes nas cidades, e pode estar ligado a um conjunto de equipamentos públicos de caráter cultural ou institucional.

- Parque natural constitui área protegida por lei, onde indústrias são proibidas e residências são restritas, admitidas as comunidades tradicionais ou nativas que comprovadamente habitavam a região antes do surgimento do parque. Muitos parques naturais - cujo objetivo central é preservar a natureza, particularmente a flora e a fauna - tornam-se centros turísticos por abrigarem relevante patrimônio natural.

- Parque Nacional é uma reserva, geralmente de propriedade pública, cujo objetivo é preservar os ecossistemas naturais de grande relevância ecológica e beleza cênica, viabilizando pesquisas científicas e atividades de educação e interpretação ambiental.

No Brasil, os Parques Nacionais, Estaduais e Municipais integram o Sistema Nacional de Unidades de Conservação - SNUC.

Todavia, quando determinadas áreas são reconhecidas como "parque patrimonial" (industrial, agrário, fluvial etc.), o são por conformarem uma paisagem específica. Dessa forma, o termo parque assume a expressão de uma paisagem em territórios não necessariamente contínuos e nem com dimensões padronizadas. Portanto, um parque patrimonial constitui-se em modelo de desenvolvimento territorial que envolve sustentabilidade e as identidades locais, respeitando os processos da paisagem correspondente.

O binômio "patrimônio-paisagem", concebido como o motor propulsor de uma sociedade sobre o seu território, leva à compreensão que se deve ter sobre o ordenamento territorial. Conforme Sabaté Bel (2004), a gestão inteligente de um território e sua correspondente paisagem tem se convertido em instrumento eficaz de promoção econômica, tal como se observa nos parques agrários, parques fluviais e ecomuseus existentes na Europa e Estados Unidos. Por sua vez, Lynch (1960) ressalta que a cada instante,
(...) há mais do que o olho pode ver, mais do que o ouvido pode ouvir, um cenário ou uma paisagem esperando para serem explorados [...] quase todos os sentidos estão em operação, e a imagem é uma combinação de todos eles (Lynch 1960, p. 01-02).

No nordeste dos Estados Unidos, onde a industrialização é mais antiga, desenvolveu-se um importante know-how para a promoção do patrimônio industrial em um contexto de mercado turístico competitivo. Tais iniciativas contam com o amparo de leis e programas de cooperação técnica e financeira.

O Programa das Áreas do Patrimônio Nacional, em funcionamento desde 1996, dá cobertura aos processos que recuperam as paisagens nacionais e de reconhecimento distinto pelo Congresso dos Estados Unidos (Casas 2004, p. 411).

Das análises mais aprofundadas sobre os diferentes projetos de parques patrimoniais realizados no mundo todo, conclui-se que uma competente gestão dos recursos patrimoniais surge como um dos fatores chave para o desenvolvimento econômico - e territorial - sustentável, porque atrai turismo e investimento, gera atividades e postos de trabalho, mas o principal é que reforça a autoestima da comunidade (Sabaté Bel 2010, p. 23).

Os parâmetros utilizados nos projetos europeus de parques patrimoniais poderiam ser aplicados também para os parques brasileiros - agrários, fluviais ou geológicos - se analisados passo a passo visando uma abordagem abrangente sobre a questão dos parques no contexto do ordenamento territorial. Cabe observar que um mesmo parque patrimonial poderia abranger e integrar diferentes parques - geológicos, fluviais ou agrários. Cabe uma profunda reflexão a respeito das relações entre cultura e o território onde ela se expressa, procurando reconhecer os aspectos presentes e relevantes a fim de:

(...) superar uma posição meramente conservacionista do patrimônio e trabalhar com os recursos dentro dos processos de transformação. A construção de hoje pode também gerar a identidade e o patrimônio de amanhã. Paisagem e território não como mero suporte, e sim como fator básico de qualquer transformação (Sabaté Bel 2004, p. 49).

Elaborado por Braga (2011), o Quadro 1 sintetiza as dez ações e respectivas abordagens propostas por Joaquín Sabaté Bel (UPC \& MIT, 2001) visando a concepção de projetos de parques patrimoniais. 


\section{Parques agrários integram cultura, produção agrícola e desenvolvimento local}

O conceito de parque agrário estabelece os alicerces de um instrumento de gestão das áreas agrícolas sujeitas a uma grande pressão urbana. Assim, o ordenamento do território se destaca como um dos principais objetivos de um parque agrário, tanto quanto o próprio desenvolvimento da atividade agrícola. A concepção desse tipo de parque se baseia em redes de cooperação, que por sua vez se estruturam na receptividade dos agentes envolvidos, bem como no acordo para se manter o contato uns com os outros, coordenar atividades e compartilhar responsabilidades (Braga 2011).

Quadro 1. Parâmetros de projeto para parques patrimoniais.

\begin{tabular}{|c|c|c|}
\hline PASSOS & AÇÕES & ABORDAGEM \\
\hline 1 & $\begin{array}{l}\text { Definir objetivos básicos } \\
\text { da intervenção }\end{array}$ & $\begin{array}{l}\text { Sugerir a integração respeitando as características do território, considerando } \\
\text { diferentes funçôes: preservação, educação, limites, turismo e desenvolvi- } \\
\text { mento econômico. }\end{array}$ \\
\hline 2 & $\begin{array}{l}\text { Explicar a história da } \\
\text { região }\end{array}$ & $\begin{array}{l}\text { Cada território exprime uma determinada interpretação, geralmente espe- } \\
\text { cífica, coerente com os recursos disponíveis. Por exemplo, a organização de } \\
\text { uma comunidade rural: a história e a interpretação da paisagem são impres- } \\
\text { cindíveis para integrar os recursos patrimoniais, a fim de que interpenetrem } \\
\text { e se reforcem mutuamente, para situar o turista, o estudioso, o usuário em } \\
\text { relação à rota geral do parque. }\end{array}$ \\
\hline 3 & $\begin{array}{l}\text { Definir um âmbito } \\
\text { coerente e sub-âmbitos } \\
\text { como um fio condutor }\end{array}$ & $\begin{array}{l}\text { Um dos primeiros aspectos que se aborda nesses projetos é a delimitação } \\
\text { precisa e justificada do âmbito; em função de seus recursos e sua história, } \\
\text { de sua singularidade, daquilo que se faz merecedor de preservação, reinter- } \\
\text { pretação e valorização. Deve-se demonstrar a pertinência de relacionar os } \\
\text { episódios físicos e temáticos diversos, relacionando-os por meio de um elo } \\
\text { condutor de modo a manter a coerência conceitual e histórica. }\end{array}$ \\
\hline 4 & $\begin{array}{l}\text { A viagem, a rota e a ima- } \\
\text { gem como elementos } \\
\text { críticos }\end{array}$ & $\begin{array}{l}\text { É imprescindível vincular os recursos associados à história comum por meio } \\
\text { de itinerários a pé, a cavalo, em barcos, ou a bicicleta, posto que a experiên- } \\
\text { cia do percurso, ao seguir a rota é fundamental. }\end{array}$ \\
\hline 5 & $\begin{array}{l}\text { Documentação rigorosa } \\
\text { para narrar a história do } \\
\text { parque }\end{array}$ & $\begin{array}{l}\text { A história a ser narrada há de ser original, coerente com os recursos de que } \\
\text { dispõe, e fundamentalmente bem documentada. A maioria dos projetos não } \\
\text { prescinde de um rigoroso inventário dos recursos patrimoniais. Estes são } \\
\text { os ingredientes básicos para narrar um processo de interpretação, e ao seu } \\
\text { modo, são os principais atrativos para visitantes potenciais. }\end{array}$ \\
\hline 6 & $\begin{array}{l}\text { Os habitantes da região } \\
\text { do parque constituem } \\
\text { um dos principais recur- } \\
\text { sos naturais }\end{array}$ & $\begin{array}{l}\text { Os habitantes locais são essenciais ao futuro de um parque patrimonial, } \\
\text { tanto por seus conhecimentos, recordações e histórias, como pelo entusias- } \\
\text { mo, uma vez que reconhecem o valor do patrimônio acumulado. O reforço } \\
\text { da autoestima leva-os a empenharem-se na construção de um futuro melhor } \\
\text { com base na gestão dos recursos patrimoniais. }\end{array}$ \\
\hline 7 & $\begin{array}{l}\text { Emergir da própria re- } \\
\text { gião iniciativas de cola- } \\
\text { boração }\end{array}$ & $\begin{array}{l}\text { Exemplos relevantes de parques patrimoniais foram aqueles impulsionados } \\
\text { por agentes locais, amantes de um território que valoriza seus recursos. As } \\
\text { melhores iniciativas se caracterizam por virem de baixo para cima. }\end{array}$ \\
\hline 8 & $\begin{array}{l}\text { A associação de várias } \\
\text { administrações é um } \\
\text { valor }\end{array}$ & $\begin{array}{l}\text { Geralmente as iniciativas locais mobilizam diferentes níveis administrativos } \\
\text { e números de atores, o que implica em sobreposições de competências e } \\
\text { relações às vezes bem complexas. Fontes de financiamento diversas podem } \\
\text { atuar a favor do projeto. Todavia é necessário criar lugares de encontro, pla- } \\
\text { taformas de comunicação, de participação e intercambio entre as diferentes } \\
\text { instâncias públicas, e também entre agentes públicos e privados. }\end{array}$ \\
\hline 9 & $\begin{array}{l}\text { Geralmente é mais im- } \\
\text { portante um reconheci- } \\
\text { mento oficial do que um } \\
\text { subsídio econômico }\end{array}$ & $\begin{array}{l}\text { É desejável o reconhecimento oficial com subsidio econômico. Há tipos } \\
\text { diferentes de reconhecimento, de atribuição pública de valor singular, como } \\
\text { a denominação de Reserva da Biosfera ou Patrimônio da Humanidade. }\end{array}$ \\
\hline 10 & $\begin{array}{l}\text { Uma estrutura física } \\
\text { clara }\end{array}$ & $\begin{array}{l}\text { 1) âmbito global e sub-âmbito do parque; 2) os recursos patrimoniais e os } \\
\text { serviços do parque, grifes do parque; 3) os portões e os acessos, os centros de } \\
\text { informação e os museus do parque; 4) os caminhos internos do parque e as } \\
\text { ligações dos pontos nodais, os itinerários; 5) os limites visuais e administrati- } \\
\text { vos do território do parque, as fronteiras. }\end{array}$ \\
\hline
\end{tabular}


O Parque Agrário do Baixo Llobregart em Barcelona (Espanha) é produto de um longo processo de debate e reflexão sobre o fenômeno da periurbanização na Europa, e de pesquisas para os modelos de preservação e gestão de áreas periurbanas agrícolas. Constituem objetivos do projeto desse parque a preservação do espaço agrário, a promoção e o desenvolvimento econômico resultante das atividades agrícolas da região, e ainda, confirmar a vocação de um excepcional espaço de lazer e educação ambiental, que procura manter as áreas cultivadas e naturais a fim de que exerçam a função de pulmão da área metropolitana de Barcelona.

De acordo com UPC \& MIT (2001), as linhas estratégicas propostas para consolidar e desenvolver a atividade agrícola, integrar o meio ambiente e promover experiências sociais dentro da região agrícola onde seria implantado o parque levaram a uma série de atitudes que se materializaram no projeto, como:

- Propor a modernização das operações agrárias e melhorias na infraestrutura preexistente (estradas, redes de irrigação, qualidade e reutilização da água etc.), e serviços gerais (vigilância rural, fornecimento de óleo diesel etc.).

- Promover os sistemas de produção e marketing visando maior competitividade.

- Recuperar as áreas danificadas pela presença de atividades não agrícolas.

- Monitorar a qualidade ambiental (integrando gestão e produção ecológica, resíduos zero, sistemas de irrigação eficientes etc.) e comercialização (marcas de qualidade, Indicação Geográfica Protegida etc.) que impulsionam o aumento da renda agrícola.

- Melhorar a relação entre atividade agrária e preservação dos espaços naturais, desenhando ferramentas adequadas para eliminar possíveis incompatibilidades (centro de normalização dos produtos, acordos com cooperativas e associações de proteção de culturas vegetais, melhoria dos pontos de venda etc.).

- Planejar os espaços e acessos públicos ao parque agrícola.

- Difundir as produções ecológicas e culturais do parque agrário a fim de promover a consciência social e a atração turística.

- Programar para consolidar e promover o patrimônio natural e cultural do parque agrário, sem interferir na atividade agrícola (programas educativos para escolas, programas agroterritoriais, centros de interpretação ambiental etc.).

O estudo sobre parques agrários dá a dimensão de como áreas agrícolas periurbanas podem ser integradas no contexto de grandes metrópoles, ou mesmo de pequenas e médias cidades, de maneira a estabelecer uma "comunicação" que agrega valor - por intermédio do desenvolvimento territorial - a uma nova condição de vida e do lazer (Braga 2011).

Portanto, as áreas agrícolas nas franjas urbanas das grandes cidades nem sempre estão fadadas a desaparecer ou se transformar em condomínios residenciais. Um modelo de desenvolvimento e gestão coerente para com essas áreas permite que elas possam continuar alimentando as cidades, ao mesmo tempo em que são alimentadas por essas mesmas cidades, estabelecendo um fluxo de interesses mútuos no contexto do planejamento regional. Os parques agrários, assim como outros parques patrimoniais, constituem uma boa alternativa para a consecução de tal sistema territorial.

\section{Parques fluviais integradores de sistemas hídrico-territoriais}

Os parques fluviais constituem modelo de desenvolvimento territorial sustentável respeitando as identidades locais e procurando entender os processos que constroem a paisagem. A tabel apresenta a abordagem metodológica de dois parques fluviais europeus e de dois projetos no Brasil.

No Brasil, de acordo com o Ministério do Meio Ambiente, os parques fluviais difundiramse inicialmente no Rio de Janeiro a fim de coibir a degradação das margens causada principalmente pelas ocupações ao longo dos rios fluminenses. Neste caso, a ideia de parque fluvial estaria sempre relacionada a uma estratégia para uso e proteção das margens de um rio. Constitui-se assim como eficiente instrumento de conservação e preservação das bacias hidrográficas situadas, principalmente, em áreas urbanas, contribuindo para com a articulação dos diversos atores sociais nessas bacias.

Todavia, o conceito de parques fluviais utilizado na Europa é mais abrangente, permitindo caracterizá-los como instrumento legal de proteção ambiental capaz de promover o ordenamento territorial e proteger o patrimônio hídrico por meio de uma gestão competente, participativa, 
sustentável e econômica (Braga, 2017). Para empregar tal conceito há que se caracterizar as dimensões econômica, social, ambiental e cultural da água, seu status de patrimônio da humanidade, a valoração que se lhe atribui e a conversão do patrimônio hídrico em recurso hídrico. As políticas públicas de desenvolvimento regional sustentável com foco na gestão integrada dos recursos hídricos e no ordenamento territorial exigem novas formas de participação da sociedade civil na gestão da água.

\section{Os geoparques integram ordenamento territorial a um desenvolvimento regional sustentável}

O conceito de ordenamento territorial, embora seja amplo e complexo, pode ser aplicado ao planejamento e organização do uso de um território de tal modo a permitir o compartilhamento equilibrado entre as atividades de caráter econômico, social, cultural e ecológico. No Brasil há um arcabouço legal apropriado à geoconservação, mas há também uma lacuna no entendimento da população e governantes da real importância de se preservar sítios por sua singularidade geológica (Mansur 2010). Deveria haver uma maior conscientização sobre o imenso e valioso patrimônio geológico e territorial do Brasil, ação essencial para a geoconservação.

O ordenamento territorial deficiente inviabiliza a implantação e gestão de "cidades sustentáveis" bem como a conformação de "territórios sustentáveis" - compostos por cidades sustentáveis numa mesma região onde o espaço não-urbano é gerenciado de acordo com as boas práticas da ges- tão ambiental. Todavia, o ordenamento territorial é condição essencial para um projeto sustentável. O planejamento de territórios sustentáveis possui necessariamente um caráter transdisciplinar pois induz a estudos aprofundados sobre o desenvolvimento urbano e rural adaptando conceitos que delineiam uma região ecológica e economicamente integrada (Ferrão 2016). Portanto, há que se considerar o território como um dos maiores bens de um povo. Território é patrimônio.

O Instituto do Patrimônio Histórico e Artístico Nacional (IPHAN), juntamente com outras entidades do poder público e sociedade civil, devem assumir a responsabilidade pelo patrimônio natural no Brasil. O IPHAN atua na preservação de áreas de valor geológico e paleontológico por meio do tombamento de sítios e coleções, e desde 2009 incrementa a sua ação por meio da instituição da chancela da "Paisagem Cultural Brasileira", um novo e poderoso instrumento de gestão territorial. Os geoparques constituem um modelo para o IPHAN poder exercer suas atribuições legais e atuar de forma compartilhada, amparado no reconhecimento internacional (Delphim 2009).

O termo "geoparque" vem sendo utilizado no Brasil para a designação de sítios de amplo interesse geológico e paleontológico. Contudo, o sensu UNESCO (2010) parte dos pressupostos de uma estratégia territorial. Assim, os geoparques compõem uma iniciativa de conservação e desenvolvimento científico, social e educacional de uma região de potencial cênico natural. Todavia, para sua implementação, é necessário haver uma equipe interdisciplinar de planejamento e o apoio

Tabela 2. Abordagem metodológica de parques fluviais no Brasil e na Europa.

\begin{tabular}{|c|c|c|}
\hline Parque & Partido do projeto & Base metodológica do projeto \\
\hline $\begin{array}{l}\text { [Alemanha 1999] } \\
\text { Parque Fluvial IBA Emscher. } \\
\text { Renânia do Norte, Vestfália }\end{array}$ & $\begin{array}{l}\text { Projeto para a renovação } \\
\text { de uma antiga região in- } \\
\text { dustrial }\end{array}$ & $\begin{array}{l}\text { Área de intervenção transformada para atender a } \\
\text { novos usos do lazer e preservar a história da região } \\
\text { industrial }\end{array}$ \\
\hline $\begin{array}{l}\text { [Espanha 2001] } \\
\text { Parque Fluvial do Llobregatt. } \\
\text { Barcelona, Catalunha }\end{array}$ & $\begin{array}{l}\text { Colônias com característi- } \\
\text { cas residenciais, agrícolas e } \\
\text { industriais, porém com o } \\
\text { envelhecimento produtivo }\end{array}$ & $\begin{array}{l}\text { Paisagem Cultural como instrumento fundamental } \\
\text { para o planejamento e o desenvolvimento regional, } \\
\text { o parque inspira o planejamento urbano tendo como } \\
\text { objetivo o desenvolvimento econômico e a melhoria } \\
\text { da área }\end{array}$ \\
\hline $\begin{array}{l}\text { [Brasil 2007] } \\
\text { Parques Fluviais Rio Guandu. } \\
\text { Região Metropolitana do Rio de } \\
\text { Janeiro }\end{array}$ & $\begin{array}{l}\text { Programa de preservação } \\
\text { de bacias hidrográficas }\end{array}$ & $\begin{array}{l}\text { Ações voltadas ao incentivo do lazer e do turismo } \\
\text { com a instalação de equipamentos urbanos e o plan- } \\
\text { tio de árvores nas margens dos rios }\end{array}$ \\
\hline $\begin{array}{l}\text { [Brasil 2009] } \\
\text { Parque Fluvial de Bom Jesus da } \\
\text { Lapa. } \\
\text { Minas Gerais e Bahia }\end{array}$ & Parque lineares & $\begin{array}{l}\text { Preservar e revitalizar os recursos naturais da região, } \\
\text { melhorando a qualidade da água e desenvolvendo } \\
\text { programas de reflorestamento e atividades de cultura, } \\
\text { lazer, esporte, turismo e educação ambiental }\end{array}$ \\
\hline
\end{tabular}


de autoridades competentes (Onary-Alves et. al. 2015). Nesse sentido, pode-se dizer que o conceito de "geoparque" se coaduna perfeitamente com o de "parques patrimoniais", incluindo nesse conjunto a ideia de "parques fluviais" e "parques agrários".

A fim de buscar a integração dos conceitos de geoparque com os de parque fluvial (particularmente de acordo com a visão europeia de parque fluvial), Oliveira \& Ferrão (2011) procuraram caracterizar o Patrimônio Natural Geológico como um componente fundamental da paisagem fluvial na Bacia Hidrográfica do Sorocaba e Médio Tietê $\left(\right.$ BHSMT) ${ }^{1}$ a partir da abordagem sistêmica e do pensamento orientado a processos, formatando como proposta de projeto um parque fluvial como entidade integradora dos parques existentes na região, com destaque para os seguintes elementos ou sistemas: o "Canyon" (Estrada-parque Cabreúva-Itu); os Matacões; o Parque do Varvito; o Parque Rocha Moutonnée; e o Paredão Rochoso (Parque das Monções em Porto Feliz).

Por sua vez, Ferrão \& Braga (2015) também chamaram a atenção para a relevância do imenso patrimônio geológico da região do Médio Tietê tanto no contexto nacional como no internacional. Estudando o patrimônio natural geológico presente na Bacia Hidrográfica do Sorocaba e Médio Tietê (BHSMT), os autores ratificaram a ideia de que este deve ser preservado por haver um reconhecido valor inerente. As políticas de preservação da paisagem na bacia deveriam reconhecer sua história e o seu imenso valor cultural. A conservação do maravilhoso e significativo patrimônio natural ali presente permitiria o resgate de áreas que se encontram no ostracismo, seja submetendo-as a um produto de consumo com o invólucro de parques que pode contribuir para a melhoria das localidades mais diretamente envolvidas no processo, seja como uma área distinta para estudos científicos, educação ambiental e patrimonial, cultura e lazer (Oliveira \& Ferrão 2011).

\section{Conclusão}

O projeto de um parque fluvial, além de revitalizar o rio, deve promover a integração entre o ambiente construído e o patrimônio cultural, respeitando os sistemas naturais. Deve promover a

1 Os autores apresentaram um trabalho resultante deste mesmo estudo na forma de Poster durante o / Simpósio Brasileiro de Patrimônio Geológico (Rio de Janeiro, 14 a 17 de setembro de 2011). reutilização adaptativa das paisagens e dos edifícios industriais específicos, se existentes na região, e estimular o uso misto que reforça as relações entre produção e comércio, proporcionando acesso direto aos elementos naturais, serviços e infraestrutura do parque. Deve seguir um programa de atividades diversificado composto por várias dimensões de ação (ou seja, uma mistura de atividades programadas e não programadas), disponíveis para o dia e para a noite, e orientado para todas as idades. De maneira análoga pode-se discriminar essas mesmas características essenciais nos projetos europeus de parques agrários e também nos geoparques. O fator que unifica o partido desses projetos é a característica intrínseca de serem todos essencialmente "parques patrimoniais".

Para a implantação de um parque patrimonial (agrário, fluvial ou geológico) em determinada região há que se buscar fontes de financiamento diversas que possam viabilizar o projeto do parque, com as diferentes instâncias públicas, e entre agentes públicos e privados. Há que se fazer um inventário dos recursos ambientais e culturais da região. Todavia, há que se buscar também um financiamento criativo que pode ser alcançado por meio do desenvolvimento gradual, cobrando taxas de adesão, permitindo que os indivíduos financiem (custeio) os elementos (equipamentos e construções) específicos do parque, e ações para angariar fundos em festivais, eventos etc. Para isso, o apoio público é necessário e pode ser gerado por meio de eventos anuais com participação ativa da comunidade e governança regional que envolva toda a sociedade.

No âmbito do território há conflitos e dificuldades a serem superados. Os Planos de Bacias Hidrográficas e os Planos Diretores Municipais nem sempre conseguem garantir instrumentos que promovam a implementação de políticas integradas entre os municípios de uma mesma bacia. Há que se criar condições para o planejamento e a gestão integrada das políticas públicas urbanas e regionais. O projeto de um grande parque patrimonial em escala regional pode facilitar essa integração, na medida em que o parque só se viabiliza se os mencionados planos estiverem harmonicamente integrados.

É importante promover estudos contínuos e aprofundados no meio acadêmico e no âmbito da sociedade civil a fim de se criar uma massa crítica consciente sobre a pertinência de se implantar um parque patrimonial (agrário, fluvial ou geológico) 
em determinada bacia hidrográfica ou região administrativa. Há que se ter em mente a valorização do meio ambiente e do patrimônio hídrico da região. Deve-se definir competências e o papel das entidades públicas e privadas, das organizações sociais, dos moradores locais e cidadãos para a gestão da paisagem e a promoção do patrimônio regional (natural e cultural), garantindo a sustentabilidade do projeto com base na conservação do sistema hídrico-territorial. Um parque patrimonial é o território das águas.

\section{Referências}

Brasil 1997. Lei 9.433, de 18 de janeiro de 1997. Institui a Política Nacional de Recursos Hídricos, cria o Sistema Nacional de Gerenciamento de Recursos Hídricos, regulamenta o inciso XIX do art. 21 da Constituição Federal e altera o art. $1^{\circ}$ da Lei $n^{\circ}$ 8.001, de 13 de março de 1990, que modificou a Lei $\mathrm{n}^{\mathrm{O}} 7.990$, de 28 de dezembro de 1989.

Brasil 1988. Constituição Federal do Brasil. Brasília, DF.

Brasil s./d. Ministério do Meio Ambiente. Projetos $e$ Recursos voltados às áreas de Preservacão Permanente Urbana. URL: geo.cav.udesc.br/index.php?option $=$ com docman\&task=doc. Acesso 10 out. 2014.

Braga L.M.M. 2017. Sistemas hídrico e territorial integrados a partir do eixo do rio Jundiaí, 2017. 212 f. Campinas: Fac. Engenharia Civil. Unicamp. (Tese Doutorado). URL: http://repositorio.unicamp.br/jspui/handle/ REPOSIP/322065. Acesso 20 nov. 2017.

Braga L.M.M. 2011. Parques Agrários no Baixo Jaguaribe: Arquitetura Rural da região dos Perímetros Irrigados resultante do planejamento de bacias hidrográficas, 2011. 113 f. Campinas: Fac. Engenharia Civil. Unicamp. (Dissert. Mestr.). http://repositorio.unicamp.br/ handle/REPOSIP/257843. Acesso 13.mar. 2018.

Casas P.V. 2004. La recuperación Del paisaje cultural como um proceso abierto: el caso Del Parque Fluvial Colônias Del Llobregat. Revista Ciudad y Território Estúdios Territoriales, 2004, 140p. URL http://www. eurkn.orgwww.eurkn.org. Acesso: 24 jan. 2010.

DelphimC.F.M.2009.Patrimônioculturale Geoparque. Geol. USP. Publ. Publ. Esp., 5:75-83. DOI: 10.11606/ issn.2316-9087.v5i0p75-83. Acesso 11 jun. 2016.

Franca D.T. 2009. A importância da cultura na gestão das águas doces: aspectos introdutórios. Revista Conviver. ed. especial 100 anos DNOCS, out. 2009, p. 433. URL: http://arquivos.ana.gov.br/imprensa/ artigos. Acesso 10 jan. 2013.

Ferrão A.M.A. 2016. Cidades e territórios sustentáveis, paisagens culturais e desenvolvimento regional. Labor \& Engenho 10(2):170-179. DOI: http://dx.doi. org/10.20396/lobore.v10i2.8646238.
Ferrão A.M.A., \& Braga, L.M.M. 2015. Gestão Integrada de Bacias Hidrográficas: paisagem cultural e parques fluviais como instrumentos de desenvolvimento regional. Confins (23) [en ligne], URL: http://confins.revues.org/10124. DOI: 10.4000/confins. 10124

Instituto do Patrimônio Histórico e Artístico Nacional. 2009. Portaria $N^{\circ} 127$, de 30 de abril de 2009. Estabelece a chancela da Paisagem Cultural Brasileira. URL: http:// www.prpe.mpf.gov.br. Acesso 28 mar. 2013.

Lynch K. 1960. A imagem da cidade. São Paulo: Martins Fontes, 1997. 227p.

Mansur K.L. 2010. Ordenamento territorial e geoconservação: análise das normas legais aplicáveis no Brasil e um caso de estudo no estado do Rio de janeiro. Geociências, 29(2):237-249.

Monte-Mór R.L. 2006. As teorias urbanas e o planejamento urbano no Brasil. In: Diniz C.C. \& Crocco M. eds. 2006. Economia Regional e Urbana: contribuições teóricas recentes. Belo Horizonte, UFMG. pp. 61-85.

Oliveira F.V., \& Ferrão A.M.A. 2011. O patrimônio natural geológico como um componente da paisagem fluvial no Médio Tietê - Sorocaba. Periódico Eletrônico Fórum Ambiental da Alta Paulista 7(2). DOI: 10.17271/19800827722011107.

Onary-Alves, S.Y., Kerber, B.B., Valentin, P.R., \& Pacheco, M.L.A.F. 2015. O conceito de geoparque no Brasil: reflexões, perspectivas e propostas de divulgação. Terrae Didatica 11(2):94-107.

Sabaté Bel, J. 2010. De la preservación del patrimonio a la ordenación del paisaje: intervenciones en paisajes culturales (Europa - Latinoamérica). Labor \& Engenho 4(1):10-25. DOI: https://doi.org/10.20396/ lobore.v4i1.1686

Sabaté Bel, J. 2004. De la preservación del patrimonio a la ordenación del paisaje. Urbano 7(10):42-49. URL: http://revistas.ubiobio.cl/index.php/RU/article/ view/525. Acesso 25 nov. 2017.

Santos M. 2006. A Natureza do Espaço: Técnica e Tempo, Razão e Emoção. $4^{a}$ ed. São Paulo, Edusp. 384 p.

Santos M. 1988. Metamorfoses do espaço habitado. São Paulo, Hucitec, 124p.

Sauer C. 1925. A Morfologia da Paisagem. Martins Fontes, São Paulo, 3a. reimp., 2006, 227p.

Universidad Politécnica de Catalunya (UPC) \& Massachusetts Institute of Technology (MIT). 2001. Projectant l'eix del Llobregat: paisatge cultural $i$ desenvolupament regional $=$ Designing the Llobregat corridor: cultural landscape and regional development. Barcelona, Spain: Universitat Politècnica de Catalunya.

Venturri L.A.B. 2006. Recurso natural: a construção de um conceito. São Paulo, GEOUSP, Espaço e Tempo, (20):09-17. URL: http://www.geografia.fflch.usp. br/publicacoes/Geousp/Geousp20/Artigo_Luis.pdf. Acesso 22 maio 2015. 